\title{
Virtual Prototyping: Evaluating the Digital Twin Based Virtual Factory for New Product Introduction
}

\author{
Emre Yildiz $^{*}$, Charles Møller ${ }^{1}$, Arne Bilberg ${ }^{2}$, and Jonas Kjær Rask ${ }^{3}$ \\ ${ }^{1}$ Center for Industrial Production, Aalborg University, Fibigerstraede 16, \\ 9220 Aalborg, Denmark \\ ${ }^{2}$ Department of Technology and Innovation, University of Southern Denmark, \\ 6400 Sønderborg, Denmark \\ ${ }^{3}$ DIGIT, Aarhus University, Department of Electrical and Computer Engineering, \\ Finlandsgade 22, 8200 Aarhus N, Denmark
}

ey@mp.aau.dk, charles@mp.aau.dk, abi@iti.sdu.dk, jkr@ece.au.dk

\begin{abstract}
Shortening lifecycles and increasing complexity make product and production lifecycle processes more challenging than ever for manufacturing enterprises. Virtual Prototyping (VP) technologies promise a viable solution to handle such challenges in reducing time and physical builds as well as increasing quality. In previous studies, the Digital Twin (DT) based Virtual Factory (VF) concept showed significant potential to handle co-evolution by integrating 3D factory and product models with immersive and interactive 3D Virtual Reality (VR) simulation technology as well as real-time bidirectional data synchronisation between virtual and physical production systems. In this article, we present an extension to the paper "Demonstrating and Evaluating the Digital Twin Based Virtual Factory for Virtual Prototyping" presented at CARV2021. The study presents an evaluation by industry experts of the DT based VF concept for VP in the context of New Product Introduction (NPI) processes. The concept is demonstrated in two cases: wind turbine blade manufacturing and nacelle assembly operations at Vestas Wind Systems A/S. The study shows that the VF provides an immersive virtual environment, which allows the users to reduce the time needed for prototyping. The industry experts propose several business cases for the introduced solution and find that the phases that would have the most gain are the later ones (production) where the product design is more mature.
\end{abstract}

Keywords: Virtual Factory, Digital Twin, Virtual Prototyping, Virtual Reality, Simulation and Modeling, Industry 4.0.

\footnotetext{
* Corresponding author

(C) 2021 Emre Yildiz, Charles Møller, Arne Bilberg, and Jonas Kjær Rask et al. This is an open access article licensed under the Creative Commons Attribution License (http://creativecommons.org/licenses/by/4.0).
}

Reference: E. Yildiz, C. Møller, A. Bilberg, and J. K. Rask "Virtual Prototyping: Evaluating the Digital Twin Based Virtual Factory for New Product Introduction” Complex Systems Informatics and Modeling Quarterly, CSIMQ, no. 29, pp. 1-16, 2021. Available: https://doi.org/10.7250/csimq.2021-29.01

Additional information. Author ORCID iD: E. Yildiz - orcid.org/0000-0003-3002-0873, Ch. Møller - orcid.org/0000-00030251-3419, A. Bilberg - orcid.org/0000-0002-4780-8459, and J. K. Rask - orcid.org/0000-0002-8926-1826. PII S225599222100163X. Received: 19 July 2021. Accepted: 13 December 2021. Available online: 31 December 2021. 


\section{Introduction}

Forces like innovation and technology, competition, changing demands, and regulations are among the main dynamics that shape the evolution of industries [1]. The specific rhythm of the evolution in each manufacturing industry occurs in three domains: products, processes, and systems [2]. Therefore, companies need to handle concurrent evolution (co-evolution) of product, process, and system models to achieve the capability to adapt to their respective industrial environments [3]. However, the increasing frequency of changes results in shorter product and production lifecycles and shifting of decision-making from companies to customers, which results in higher complexity. Thus, achieving architectural isomorphism across the product, process and organisation (system) architecture required to maintain effective alignment of an organisation with its evolving environment [4] is becoming a significant challenge for manufacturing organisations.

Physical prototype building activities during the introduction of a new product can be considered among the most critical activities to achieve and ensure architectural isomorphism. However, physical prototype builds are often highly time-consuming, costly, and complex due to the uncertain and genuine nature of models and operations. When it comes to the wind industry, wind turbine generator (WTG) manufacturing covers a wide variety of production and manufacturing operations, such as heavy metal manufacturing (towers), large-size fiberglass composite material production (blades), complex and heavy parts assembly (gearbox, nacelle, generator, etc.), and electrical and electronic systems manufacturing (control and grid infeed systems). Therefore, physical prototype builds during the New Product Introduction (NPI) are becoming much more challenging for companies such as Vestas Wind Systems A/S (later Vestas). Moreover, despite the particularities of the WTG manufacturing operations, there are significant similarities with various other industries, which can provide a sound basis for the generalisability of the knowledge discovered in this study. WTG tower manufacturing, for instance, incorporates noteworthy similarities with the heavy steel fabrication operations of the aerospace, construction, maritime, and oil and gas industries. WTG blades manufacturing contains unique characteristics, reaching 107 meters in length for a single piece of fiberglass composite product, which is one of the largest in the world [5]. In terms of size, WTG blade production has some similarities with maritime production, such as superyachts [6]. Meanwhile, the global fiberglass market value reached 13 billion USD as of 2020 and is expected to reach 18.6 billion USD by 2027, mainly driven by the automotive and construction industry [7]. While gearbox, generator, and nacelle manufacturing shares similar genetics with the automotive and heavy machinery industries, the converter and control systems of WTGs incorporate similar approaches to those of various electrical and electronic manufacturing industries.

Although there are significant affinities between WTG manufacturing operations and other industries like the automotive, aerospace and maritime industries, WTGs are still not mature products and are continuing to evolve rapidly, together with the associated manufacturing systems and processes. In terms of size and weight, for instance, modern cars, ships, and planes are not substantially different from the same products manufactured in the 1980s. WTGs, however, have now reached rotor sizes of over 200 meters from 10 meters in the 1980 s, and over 400 tons of nacelle weight from 5 tons in the 1980s [8], [9]. Despite the tremendous increase in the sizes and weights of WTGs during the last four decades, the (onshore) wind energy cost per kilowatt/hour decreased to 0.05 USD from 0.4 USD during the same period [10]. Thus, the cost per megawatt oriented tendering approach results in significant pressure on WTG manufacturing companies to improve the performance of their turbines by redesigning their products, together with the associated processes and manufacturing systems. In this regard, the Digital Twin (DT) based Virtual Factory (VF) concept [11] is becoming a highly relevant solution by enabling integration, interoperability, and interaction capabilities across product and production lifecycle processes in virtual environments [12]. 
In recent studies, the DT based VF is considered a promising solution to deal with coevolution problems with its potential to achieve dynamic, open, holistic, and cognitive system capabilities [12], [13]. Moreover, industry experts considered Virtual Prototyping (VP) among the highest value promising industrial use cases for the DT based VF concept [12]. Although a virtual prototype as a computer simulation of a physical product covers all product lifecycle aspects, including service and maintenance [8], building and testing, the virtual prototype of NPI processes is particularly challenging due to the need for concurrent engineering and complex and ambiguous models and operations. However, due to the same challenges, VP maintains a significant potential for high value by enabling (1) early testing, (2) expensive or impossible tests, (3) fewer physical builds, (4) safer builds, (5) increased agility, (6) reduced cost, (7) complexity handling, and (8) reduced time to market [14]. Thus, the need for evaluating the DT based VF concept in more particular VP use cases was raised in [12].

It should be noted that this article is an extension to the conference paper titled "Demonstrating and Evaluating the Digital Twin Based Virtual Factory for Virtual Prototyping" presented at CARV2021 [15]. This article is distinguished from the previous one by extending the evaluation and discussion, amongst other additions.

Following the next section, which frames the scope and objectives of the work, Section 3 summarises related works on VP and VF. Section 4 describes the research methodology. Section 5 presents the results and evaluations of the industry experts, followed by the discussion and implications in Section 6 and conclusions in Section 7.

\section{Research Scope and Objectives}

In this study, we respond to the need addressed in [12] for evaluation of the DT based VF concept (introduced in [5]) in particular VP cases and thus present an evaluation of the concept in the context of NPI processes. The evaluation is established on the data gathered during group interviews with industry experts. In order to support the rigour and novelty of the work in hand, there is a need to clarify the differences between the scopes and objectives of the previous works [12] and the present work. The study in [12] was conducted to evaluate the DT based VF concept in terms of (1) achieving the cornerstones of the competence-based strategic management concept (dynamic, open, cognitive, and holistic), (2) enabling concurrent engineering of products, processes, and systems, (3) supporting shorter product and production lifecycles, (4) the usefulness, effectiveness, and consistency of artefacts [3]. Therefore, the essential premise for the arguments in [12] "is that DT based VF can support competence-based strategic management of manufacturing organisations during their adaptation to dynamic and complex environments." While performing the evaluation of the concept broadly in the scope of competence theory, knowledge about the particular aspects of the concept, including implications of collaborative VR and VP, was discovered. Discussions on VP in [12] provided some pieces of evidence for the potentially high value of using DT based VF during the NPI processes. However, there was a need for in-depth discussions and data on "how" the concept could be utilised during NPI and contribute to each phase of prototyping. Moreover, due to the comprehensive and complex nature of coordinated engineering operations during the NPI, none of the individual interviewees in [12] was confident enough about their judgements on extensive utilisation of the concept for VP operations.

Therefore, the present study is conducted by narrowing down the scope of the DT based VF evaluation and discussions on the VP context with a particular focus on NPI activities. Due to (1) the high level of coordinated engineering during NPI, which causes a limited view for an individual engineer, and (2) the diversity of manufacturing operations of WTGs, it was decided to conduct the interviews with focus groups with distinct engineering (tooling, training, design, etc.) and manufacturing (tower, blade, assembly, etc.) backgrounds. Group interviews were

\footnotetext{
${ }^{\dagger}$ https://carv2020.com/
} 
established to instigate richer arguments and discussions on an issue or a proposition by enabling the collision of diverse experiences and approaches on the same subject. Thus, the objective of the study is to conduct an exploratory work to discover knowledge on (1) how the DT based VF can be utilised in VP operations of WTG manufacturing, and (2) what benefits can be gained from such industrial implementation. Therefore, the concept is demonstrated in wind turbine blade manufacturing and nacelle assembly cases at Vestas, as in the previous work [12]. However, the evaluation was performed by a more specialised and experienced group of interviewees. In contrast to the previous evaluation, which included both higher- and lower-level experts, the interviewees in this work were mostly medium-level and technical experts with more (14.8) years of experience (compared to 11 years in [12]).

Therefore, the study draws upon previous research, including concept design and development of the VF [16], its extension with DT [11], [12] and collaborative VR capabilities [17]. Thus, we spare the reader from prolonged discussions on the concept and its design and development methodologies. However, we would strongly recommend the reader to refer to the subject studies for in-depth discussions on practical and theoretical aspects of the work.

\section{Related Works}

\subsection{Virtual Prototyping}

With the advances in Computer-Aided Design (CAD), Computer-Aided Manufacturing (CAM) and visualisation and interaction capabilities, the development of virtual environments and realistic virtual representations of product models has gained more attention from scholars and industry experts. Thus, development and interaction with such virtual models become viable solutions promising significant advantages for the industrial processes in terms of reducing time, decreasing costs, and increasing quality [18]. As a result of this, VP, a key aspect from the application point of view, is starting to get attention in both the application and knowledge domains. However, there have been many different interpretations of VP techniques, which have caused some confusion. To prevent such confusion, Wang defined a virtual prototype as " $a$ computer simulation of a physical product that can be presented, analysed, and tested from concerned product lifecycle aspects such as design/engineering, manufacturing, service, and recycling as if on a real physical model. The construction and testing of a virtual prototype is called virtual prototyping (VP)" [19]. Wang also addressed the needs for concurrent design, analysis, optimisation, and integration of simulation tools. Some studies consider VP to alleviate the shortcomings of rapid prototyping (RP) [20], while others stress the difference between RP and VP [21]. Alongside early adoptions in the aerospace and automotive industries [14], VP technologies are also promising significant value in different industries such as construction [22], the maritime industry [23], and heavy machinery industries [24].

Studies about VP techniques focus on different product lifecycle aspects, including product design, analysis, testing and assembly process design [25]-[28]. However, there are limited studies focusing on the VP of products from a manufacturing aspect [29]. Although scholars concentrate on various VP simulations such as structural material and structural behaviour simulations [28], [30], recent studies show more attention to immersive VR integrated simulation tools [31]. Recent review studies show that advances in simulation technologies, including realtime data integration, realistic visual representations and embedded VR and augmented reality (AR) capabilities, can make simulations a proven enabler for digital integration and access to data across the product and production life cycles [32].

In this respect, the VF concept, as high-fidelity integrated factory simulations representing factories as a whole, can provide viable virtual environments for constructing and testing virtual prototypes, since they enable the experimentation and validation of the various product, process, and system models concurrently [11]. Therefore, we will briefly present some studies focusing on VF in the next section. 


\subsection{Virtual Factory}

Since Onosato and Iwata [33], [34] introduced the integration of product and factory models as an integral aspect of VF and virtual manufacturing, various definitions have been given for VF, including emulation facility, integrated simulation and virtual organisations [35]. Jain et al. defined VF "as an integrated simulation model of major subsystems in a factory that considers the factory as a whole and provides an advanced decision support capability" [35]. An integrated VF framework concept which can synchronise the real factory and VF was introduced by Sacco, Pedrazzoli, and Terkaj [36]. While Jain et al. [37] stressed the multi-resolution capabilities of VF simulation models, Yang et al. [38] introduced the VF concept for collaborative design and analysis of manufacturing systems. There is also a higher level of utilisation of the VF concept as a collaborative business process monitoring environment for achieving business goals [39]. Yildiz and Møller [16] presented the VF concept as a more dynamic and open system by integrating VF into actual manufacturing execution and product lifecycle systems, as illustrated in Figure 1. A more distinct conceptualisation of the product, process and system domains in between the product and production lifecycle processes enables better interpretation of the link between these domains. Such representation is also considered a better way to handle complexity and improve efficiency for DT development and the fidelity of simulation models. The utilisation of collaborative VR training simulations in the VF concept, together with DT capabilities, was also studied by Yildiz et al. [11], [17]. They also considered $\mathrm{VF}$ as "an immersive virtual environment wherein digital twins of all factory entities can be created, related, simulated, manipulated and communicate with each other in an intelligent way" [16]. A comprehensive demonstration of the DT based VF concept in industrial cases [12] showed significant potential for the concept to handle co-evolution and called for more particular evaluation in VP cases.

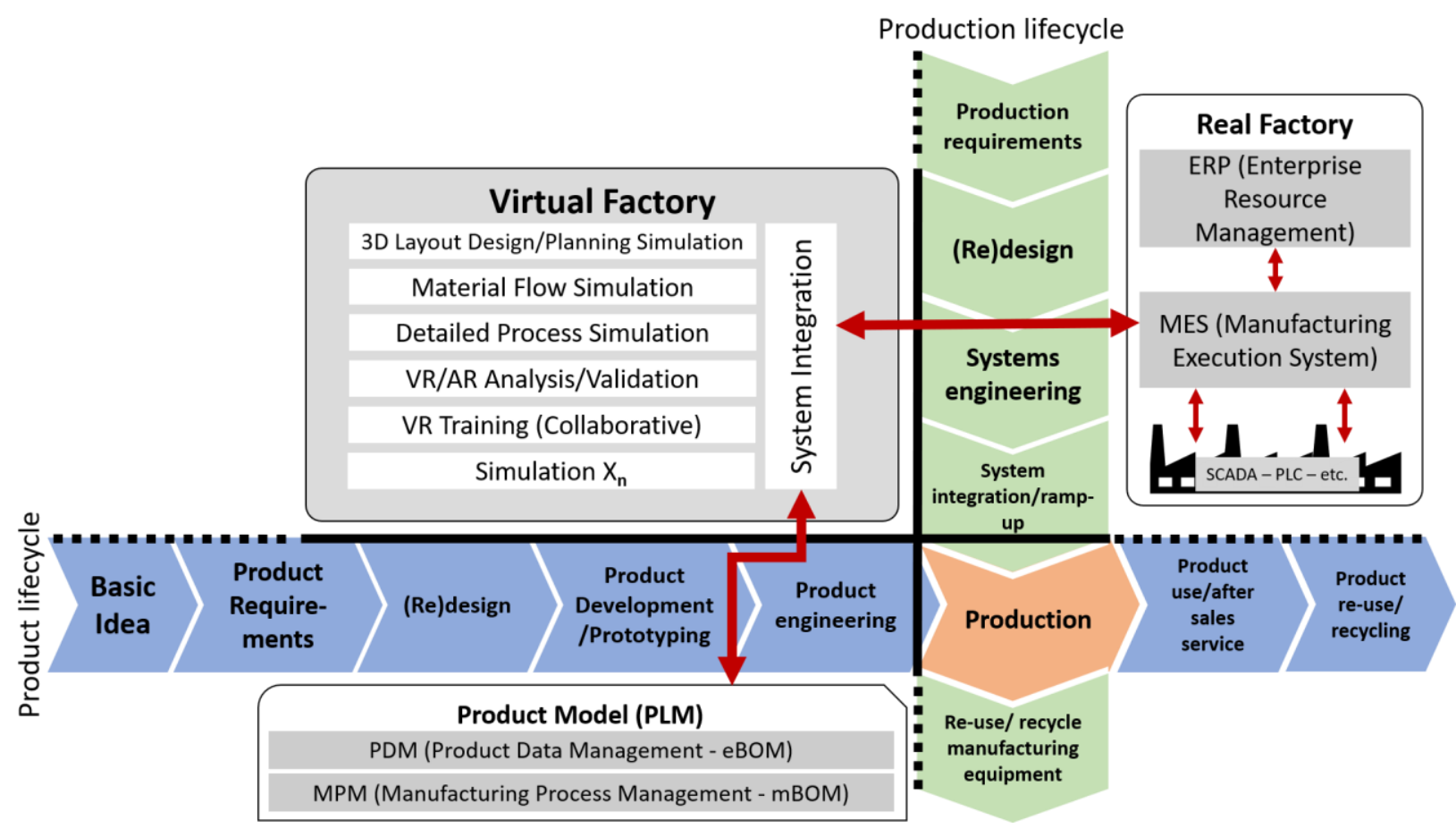

Figure 1. Digital Twin based Virtual Factory concept [12]

In this regard, we further discuss the methodology for the demonstration of the DT based VF concept in wind turbine blade manufacturing and nacelle assembly cases, as well as its evaluation in the context of VP in NPI processes. 


\section{Methodology}

There are two exercises of the knowledge, which are (1) creation of the knowledge and (2) applying the knowledge [40, p. 3]. Knowledge about natural phenomena is discovered/created by applying scientific methods like experimentation, observation, and empirical evidence collection. Such descriptive knowledge about nature enables the manipulation of the same nature by utilising purposefully designed physical (tools, machines, etc.) or conceptual artefacts (models, methods, etc.) [44]. When such artefacts take physical forms, it is usually called technology. The consequence of manipulating natural phenomena is the emergence of new scientific methods, discoveries and thus new knowledge [45]. Since it is not possible to provide an in-depth discussion on science-technology dualism in this work, it is important to stress that the subject study aims to discover prescriptive knowledge, which is demonstrated in the utility, effectiveness, reliability, consistency, etc. of the designed artefact.

Since this study aims to explore the practical usefulness of a conceptual design in empirical cases, Design Science Research Methodology (DSRM) is considered a well-suited methodology. Thus, the research demands instrumental knowledge to uncover the effects of interventions on a manufacturing enterprise's specific (NPI) operations. Various research works which have been carried out over the last three years were conducted on the trails of guidelines, methods, and frameworks of DSRM [41]-[44]. However, this article covers only the demonstration and evaluation activities of six DSRM activities. Since the designed artefacts should have an impact on the practice, the design science research objective of the present paper is to report the kinds of impact of the IT artefact and design theories.

Four demonstration and evaluation sessions were conducted, each with five participants, with a total of 20 participants. A session covered (1) presentation of the artifacts, tools, and capabilities, (2) live demonstration of DT based VF, including VR interaction, and (3) semistructured group interviews. Therefore, the demonstration and evaluation methods are briefly articulated in the following sub-sections.

\subsection{Demonstration}

Demonstration of general artefacts (concepts, architectures, methods, demo) delineates how to use the developed artefacts effectively in particular contexts. Therefore, although the discovered knowledge will be about the particular context, it should be able to transfer into various contexts within the same application domain without losing its necessary effectiveness [43]. In this study, DT based VF is demonstrated in two diverse cases, including large composite manufacturing (blade) and complex and heavy parts assembly (nacelle) at Vestas. Although such cases are unique to the wind turbine manufacturing industry, there are significant common aspects with various industries such as shipbuilding, automotive, and aviation. Thus, the knowledge can provide guidelines for experienced professionals in the industry and enable the evaluation of deviations in the form of "if-then" specific to each context.

Since the DT based VF is a generic concept, and the capabilities and implications of the implemented concept depend on the context-specific tools, data and IT infrastructure, a short presentation was made to explain and distinguish the concept, tools, technologies, demo, and methods. Some parts of the data about the demonstration are subject to the intellectual and financial interest of Vestas. Thus, a significant part of the data is covered by the provisions given to Vestas by the research collaboration agreement. However, we strongly advise the readers to access the part of the demonstration video that is publicly available via [46]. The video shows examples of DT based VF simulations that are synchronised with process data from the real factory via the manufacturing execution system. The synchronisation allows the reflection of changes in VFs to produce manufacturing data analysis based on timings from the real factory. Furthermore, the video shows that you can manipulate the VFs in a VR environment and even have multiple users in the same VF simulation environment to perform collaborative and 
coordinated manufacturing (assembly) operations. This enables operators to train together in the virtual environment on products that may not be in production yet.

\subsection{Group Interviews}

The group interviews aim to collect data to evaluate the DT based VF concept in the context of VP during the NPI processes with well-grounded pieces of evidence and arguments by exploring the interpretations and perspectives of industry experts. During the group discussions, the interpretations of the experts were critically examined by instigating a process of reflection to gain more specific, accurate and grounded pieces of evidence. Moreover, group discussions with diverse technical expertise on similar operations in different manufacturing domains allowed the experts to reach more reliable judgements or demonstrate independence through slight disagreements.

Since the purpose of Design Science Research (DSR) is to discover the practical usefulness of a solution to deal with empirical challenges with practical methods, DSR focuses on the pragmatic validity and practical relevance of a generic design [43]. Therefore, justification of a solution concerns, including but not limited to, the effectiveness, usefulness, and consistency. In this regard, group interviews were initially planned as physical meetings to enable interviewees to experience first-hand a DT based VF demo with immersive and interactive VR environments. Unfortunately, due to the COVID-19 pandemic, live demonstrations had to be performed during an online meeting which allowed the interviewees to see the physical and virtual environments but not fully experience VR. The interviews were recorded with the Microsoft Teams software tool and transcribed with services provided by the Microsoft Stream platform. The guidelines for designing and conducting interviews by Kvale [47] were followed. The number of interviewees was limited, with five in each session to avoid uneven participation in discussions, and to acquire more valuable knowledge with more intensive interviews and penetrating interpretations. Participants were intentionally mixed for each session based on their background and department (NPI, Blade, Manufacturing, Nacelle, etc.) to increase the diversity of expertise in each session. A list of the expert interviewees is available in the appendix.

\section{Results and Evaluation}

In total, 20 interviewees participated in the demonstration and evaluation of the DT based VF concept in VP. Four sessions each included five experts and covered the introduction of the concept, demonstration, and evaluation/discussion sections, which took approximately 4 hours. Only the evaluation part of each session was recorded and took 50 minutes on average. The average years of experience of the experts were 14.8 and ranged from a minimum of 3 years to a maximum of 24 years. As anticipated, the expert discussions on the evaluation of DT based VF roamed around four terms, representing some of the main activities of NPI. These terms are (1) mock-ups, (2) design prototypes, (3) process prototypes, and (4) 0 -series production. Therefore, the results and evaluations are organised and presented under the respective headlines.

One of the recent product introduction operations at the case company comprised four mockup builds, five design prototype builds, and four process prototypes. Although the cost of the prototyping depends significantly on the magnitude of the design modifications, the cost of prototype activities of a new wind turbine on such a scale can easily reach over 10 million $€$. Some of the comments, critiques, and arguments from the industry experts are referenced to the respective participant number in the appendix. For instance, interviewee number 5 is referenced as (Int. 5). 


\subsection{Mock-up Builds}

A mock-up is an early build of the concept design, which aims to verify the functionality of the early design before the detailed design is finalised. A mock-up can be a physical or non-physical build, including a 3D model, computer simulation, hardware in the test, or a mock-up in the factory. However, if the difference in the new design is not minor compared to previous product variants, mock-up activities usually involve a significant number of physical builds. Shifting to the containerised products under the scope of modularisation, for example, could require significant changes in product design, production processes and, thus, the shop floor systems.

Most of the participants agreed that the DT based VF simulations could solve many problems and errors before early builds, but could not eliminate physical mock-up builds completely. This is mainly because NPI procedures dictate some early tests, such as a fatigue test on the physical build and a turbine test for legal certifications, requiring a minimum of three blades. Therefore, for the blade production case, it is considered that a minimum of four mock-up builds are inevitable under the present circumstances. However, 3D model simulations in factory environments were considered significantly beneficial due to increased confidence in the models (Int. 2). In addition, the majority of the experts considered that reducing the time spent on mockup builds and errors found while using VF simulations would provide sufficient value for the business case. Some stated that the significance of the time spent on design and process changes is due to the high number of issues found during the mock-up builds (Int. 10). Quoting one of the experts: "Even in early stages, this (DT based VF) could be beneficial to at least anticipate some issues that might occur in production due to design mistakes or miscalculations in design. I think that would be a great help in the decision making (on design.)" (Int. 14).

Moreover, extending the tools with a detailed and specific process and material simulations, such as material behaviours and resin injection, is considered highly valuable for the blade manufacturing case. Thus, one expert stated, "There are 1800 pieces of plies in each blade. If VF could be able to predict the tolerances, that would be a great business case." (Int. 18). Simulating the resin injection process during the WTG blade production is conventionally considered significant for the design and performance of the product. However, experts highlight that such high-resolution production processes and low-resolution factory operations have significant mutual impacts. Heat and humidity originated at the geographical location, for instance, can have a significant impact on such processes as resin injection or torque processes and, eventually overall factory operations. Thus, integrated VF simulations could enable both analyses with high-resolution simulations and synthesis with low-resolution simulations.

\subsection{Design Prototypes}

A design prototype is a physical build that represents the final design documentation and aims to verify functionality and requirements at the system, product and component level. Ideally, the design prototype should finalise and freeze the Engineering Bill of Materials (eBOM), but most likely, some corrections on the design will be made later on.

DT based VF simulations were considered more beneficial for design prototypes than mockup builds by the majority of experts since design prototypes are focused less on specific/critical materials behaviours and performances and more on the overall design integrity. It was stated by (Int. 18) that the majority of the issues (failures, corrections, improvements) faced during one of the late blade introduction processes were design-related (drawing corrections $40 \%$, cutting file corrections $24 \%$, bill of materials corrections $14 \%$, among others). Therefore, aiming to find such issues in DT based VF simulations is considered a better approach (Int. 18). On the other hand, one expert stated that "Replacing the (physical) model is not something we should consider for the near or medium future. But I think that if we could go that way, we could put a good CAD model of the product into the VF environment to do the same prototyping. So, we can play with it and test it in the weeks before the design prototype. Then I think we can lower the 
time that we spend on making the design prototype. But avoiding the design prototype completely is a bit optimistic as it is now. Considering the last design prototype, I guess VF would possibly help to decrease the time to market. We probably have several 100 issues in a design prototype. They are mostly product-related. My guess is around 10\% is the space issues (which can be solved by VF)." (Int. 11). Furthermore, the commonly agreed statement made by (Int. 17) was, "I do not think we should reduce the number of blades that we built (in prototyping processes). Yes, I know they are expensive, but I think we can improve the quality and perhaps improve the speed." Such stress on increasing quality could link to the increasing cost of downtime due to quality problems in WTGs in recent years [48].

In the nacelle assembly case, cable routing and measurements in 3D CAD models are considered a highly challenging process. "It is supercritical, especially when we try to design a cable bundle from point $A$ to point $B$, and it goes above the four different cable trays and bins. It is very difficult to draw them laying correctly on the cable tray and all the way, and that is where we see the most of the errors." (Int. 20). The impact of such challenges on the production process on the shop floor can also be considered a sign of the importance of multi-resolution simulations of the factory operations.

\subsection{Process Prototypes}

The process prototype is a physical representation that has the full functionality of the final design. The purpose of the process prototypes is to verify the various documentations of the design concerning the Health, Safety and Environment (HSE), manufacturability, production process (mBOM; Manufacturing Bill of Materials), production setup, transportation, installation, and service (sBOM; Service Bill of Materials).

DT based VF is considered highly useful for process prototypes. "Designing and modifying the production layout to find out: How to execute? How big a part of a nacelle we build and try to join them with the crane at the states. That is something we could definitely figure out in (VF) for new products." (Int. 20). However, most experts also considered the output of physical process prototypes and previous prototypes as very useful for simulating what-if scenarios and optimising 0-series and serial production processes (Int. 2). One expert stressed the importance of specific/detailed process simulations with high-level simulations by stating, "if we were be able to integrate other simulations like the infusion process with VF simulations, then we could run the blade production process right from lay-up till the curing process. The infusion process includes the material properties, the curing properties, the heating, and the moulds conditions. So, if these applications could talk to each other, then we could run the entire process within a single platform." (Int. 18).

\subsection{0-Series Production}

0 -series production is nominally the same as the serial production on the line. However, it represents the design in the line to verify the production capacity in terms of resources, tools, space, etc., and the processes capabilities to achieve the expected takt time with the proper quality requirements. The number of physical builds in 0 -series production generally depends on accelerating the learning curve and the ability to reach the target takt time.

0 -series production is considered the most effective use case for DT based VF since the design and processes are more mature in this phase. Thus, DT based VF promises high value by enabling the Vestas experts "to start up with the right sequence, the right staffing, right factory layout, and have a shorter time to market," (Int. 5) since the "use and distribution of labour throughout the blade production is extremely time-consuming." (Int. 4). Accelerating the learning curve, which represents how to produce faster, is considered highly possible. One expert stated that reaching the actual takt time for a nacelle may take three to six months and added, "VF would help to save $25 \%$ of the time of 0 -series." (Int. 11). The criticality of this issue is that 
"as soon as we get into 0-series and very short takt times, then we will notice (for example) the lack of crane capacity very quickly. The lead time for getting a new crane from the day we realise it - if we are very lucky - is four to six weeks. So that can be a very serious limiting factor. It is very valuable to see if the crane capacity is a limiting factor and it would be very useful to try out various scenarios in VF simulations." (Int. 11). Thus, DT based VF is considered very useful "to understand what the bottlenecks are to identify the risk of moving the paths or fixing the assembly sequences," (Int. 13), as well as "lean optimisations on the operators." (Int. 17).

\subsection{Other Reflections}

DT based VF is also considered for various capabilities besides simulating various prototype activities during NPI. The VR capabilities of the DT based VF were considered valuable for pretraining for large scale production roll-outs: "what if we have a new factory starting up where 1000 people are in the organisation (facility). Then we can do pre-training before we actually put them out on the mould." (Int. 17). Moreover, collaborative VR shows a sign of higher value for communication with suppliers, and it is considered very "useful to have VF during technology transfer between factories." (Int. 1). However, one expert argued that "when implementing VR, we need to be very focused on who will use it, because not everyone can work with it and that requires change management - a change of mindset." (Int. 11).

One interviewee also addressed the risk of a rapidly increasing volume of data that needs to be input to the models for achieving close-to-reality models and stressed the importance of DT technology (Int. 20). Another argued that "Approximately every 6 to 10 years we have a new generation nacelle. In between these years, the designs are very similar, and of course, it is easy to create a digital twin. But if we are introducing a new generation nacelle, it is more difficult to have a digital twin of the production." (Int. 1).

The possibility of disrupting the product development process based on the VF concept was discussed during the evaluation. Here it was mentioned that the development process follows a strict gate/tier process, where the product design is locked by the time it reaches production development. This means that tools and processes are not defined and might not be available. To reduce this issue, one expert stated that "it would be beneficial if we went as soon as the design is finished or maybe even before that, when we have the model of the product, we could start simulating the process. Maybe we should change the way we look at it and start with the tools earlier." (Int. 10).

It was also mentioned that the concept could provide safety benefits in that "there are so many safety aspects within a nacelle building, a blade building, a tower where we could utilise the safety aspects in VF as well. Also, the system could capture if VR trainees had the right safety behaviour." (Int. 17). This was further reinforced by the expert: "I have seen examples (...) where workers did the safety training through the virtual reality headset. (...) They reduced from 32 days to seven or eight days by having virtual reality training sessions. ”(Int. 17).

\section{Discussion and Implications}

The research work presented in this paper achieved the demonstration and evaluation of the DT based VF concept in the context of VP cases, particularly NPI processes. While the previous works evaluated the concept in terms of supporting the co-evolution of manufacturing enterprises, the present work focuses on the potential implications of the concept, particularly in the mock-up build, design prototype, process prototype and 0 -series production processes, which are articulated based on expert comments. The expert comments provide valuable pieces of evidence and data on how and to what extent DT based VF can support complex manufacturing operations during the NPI processes. 
Since the introduction of a new WTG into the renewable energy market is critical to compete for market share, reducing the time to market is considered strategically vital for WTG manufacturers. Therefore, there is significant pressure on coordinated engineering operations during NPI. However, the expert comments give signs that such pressure also creates significant quality problems later in the manufacturing operations and product performance. NPI engineers are simply aiming to mature their product, process, and system/organisation models from mockup build to 0 -series production. Physical prototypes provide better evidence and greater confidence to make decisions during the NPI process yet lead to significant time and cost issues. Thus, the majority of the experts assert that reducing the time to market should not be a performance indicator for utilising a solution like the DT based VF in early NPI, but instead reducing the number of issues/problems during the NPI operations. Moreover, the limitations on decreasing the physical prototype builds mean that taking this as a basis for fully eliminating physical prototypes in the near future is not realistic.

Since the bidirectional real-time data integration is inherent in the DT based VF concept, questions are raised on how to utilise the historical data of a digital twin technology for a fastchanging model. For example, the historical data of a DT could simply be irrelevant in a totally new production setup. Therefore, DT based VF is considered more valuable for later phases of NPI operations due to the larger volume of data and more mature models. Moreover, this may support the view that easy-to-use DES tools without advanced integration (with MES and PLM), and the DT capability could still be more valuable for early concept/idea simulations by enabling rapid iterations of lightweight model development and simulations.

Overall, the integration of multi-resolution simulations to represent a manufacturing system including its subsystems stands as the core capability of VF to handle evolving complexity. Such integration enables greater confidence in the impacts of major changes in overall operations from both the bottom-up and top-down approaches. Changing the WTG towers from steel to wood [49], for instance, could cause significant changes in material processing and thus the rest of operations assembly, transportation, etc. A dedicated simulation of wood processing (high resolution) could give reliable results to model and simulate the operations at the respective production line, factory, transportation, or installation (low resolution) level. Thus, the chain of reactions triggered by changes at various levels could be modelled and simulated to handle complexity in a flexible and agile way.

\subsection{Limitations and Future Work}

The work presented in this article covers only the demonstration and evaluation activities of the DSRM. The other DSRM activities, including the problem identification, definition of the objectives of the solution, design, and development activities, that were performed during the previous three years, were covered in previous studies. Thus, the reader should refer to those studies for more information to close the gap between the initial claim, which is the design and development of the DT based VF solution [11], [16], [17], and demonstration and evaluation.

Moreover, conducting a study to evaluate such a comprehensive solution in dynamic, social, and complex organisations carries the risk of internal validity confusions [50]. This is mainly rooted in the difficulty of isolating dynamic and complex manufacturing organisations that inherit a large number of interdependent variables. Such challenges limit us to performing experimental or quasi-experimental studies. Therefore, it should be kept in mind that the data in terms of articulating the capabilities of the solution and other interpretations provided by experts during the interviews are context-specific, relying on the demonstration.

It is observed that the participants were finding it hard to articulate the implications of DT based VF in high resolution manufacturing operations like specific machining, drilling, welding, and resin injection simulations. Therefore, increasing the scale of resolution in the DT based VF concept in future works could make it possible to capture more quantitative data and cases promising tangible value for the concept. 
Moreover, due to increasing size and weight, together with regulation and localisation requirements in the wind energy market, more radical solutions like moveable/containerised factories or containerised WTGs are attracting attention. Therefore, implementing the DT based VF concept in a moveable factory concept while extending the simulations with transportation, on-site assembly operations, etc. to simulate the concurrent evolution of the product, process and system/organisation as well as its impact on the value chain, promises a significant potential.

\section{Conclusion}

This article addresses the need for thorough case evaluations of the DT based VF concept in the context of VP during NPI activities. DT based VF can enable the coordinated engineering of product and production lifecycle processes by enabling the integrated representation of product, process, and systems (organisation) models for designing, verifying, optimising and interacting with such models. Although the VF is not a brand-new concept, recent developments in state-ofthe-art technologies like IoT, DT and VR and their integration into modelling and simulation tools are exploiting the potential of the VF concept exponentially. The majority of the studies on VF focus on either very specific cases and technologies or high-level conceptual work. Therefore, the present study aims to close the gap between theory and practice by exploring (1) the implications of the DT based VF in VP operations of WTG manufacturing and (2) the benefits that can be gained from industrial implementation of this concept.

The concept was demonstrated in the wind turbine blade and nacelle production facilities of Vestas and evaluated by industry experts during semi-structured group interviews. The results of the evaluation indicate that the DT based VF concept can have significant value in multiple phases of prototyping. However, the experts agree that the most value would be added in the later phases of product introduction, where this concept provides an integrated representation of the products, processes and system (factory) models. In these phases, the product design will be more mature, but the process is still at a preliminary stage. By providing the integration, the experts can discover design errors in the product and process without creating real-life prototypes. This works towards reducing the prototyping time and increasing the initial quality of the product and process. Finally, the experts address a need for an extension of the demo with more specific simulations focused on material design and behaviour (with higher resolution).

\section{Funding}

The Manufacturing Academy of Denmark (MADE) and Vestas Wind Systems A/S funded the research presented in this article, including equipment support (Grant: 6151-00006B). The authors of this article would also like to thank FlexSim for supporting our research by providing the license free of charge.

\section{Declarations}

Consent to participate: Informed consent was obtained from all individual participants included in the study.

Consent to publish: The participants provided informed consent for the publication of their statements.

Conflict of interest: No potential conflict of interest was reported by the authors and the stakeholders. 


\section{References}

[1] C. H. Fine, Clockspeed: winning industry control in the age of temporary advantage. MIT Sloan School of Management, 1998.

[2] C. H. Fine, “Clockspeed-based Strategies for Supply Chain Design,” Prod. Oper. Manag., vol. 9, no. 3, p. 210, 2000. Available: https://doi.org/10.1111/j.1937-5956.2000.tb00134.x

[3] T. Tolio et al., "SPECIES-Co-evolution of products, processes and production systems," CIRP Ann. - Manuf. Technol., vol. 59, no. 2, pp. 672-693, 2010. Available: https://doi.org/10.1016/j.cirp.2010.05.008

[4] R. Sanchez, "Architecting Organizations: A Dynamic Strategic Contingency Perspective," Res. CompetenceBased Manag., vol. 6, no. 2012, pp. 7-48, 2012. Available: https://doi.org/10.1108/S17442117(2012)0000006004

[5] The Maritime Executive, "World's Longest Wind Turbine Blade Revealed," The Maritime Executive.

[6] E. Gorgan, "World's Largest Superyacht Made of Composite Materials, Majesty 175, Premieres autoevolution," May 30, 2021. Available: https://www.autoevolution.com/news/worlds-largest-superyachtmade-of-composite-materials-majesty-175-premieres-162212.html. Accessed on Oct. 24, 2021.

[7] “Global \$18.64 Billion Fiberglass Markets to 2027: Increase," Research and Markets, Sep. $23,2021$. Available: https://www.globenewswire.com/en/news-release/2021/09/23/2301993/28124/en/Global-18-64Billion-Fiberglass-Markets-to-2027-Increase-in-Use-of-Fiberglass-Composite-in-the-Construction-andAutomotive-Industry.html. Accessed on Oct. 24, 2021.

[8] L. Bauer and S. Matysik, "Wind turbines database," wind-turbine-models.com, 2021. Available: https://en.wind-turbine-models.com/turbines. Accessed on Oct. 24, 2021.

[9] Wind Energy Market Intelligence, "Manufacturers and turbines - Online access - The Wind Power," The WindPower, 2021. Available: https://www.thewindpower.net/turbines_manufacturers_2_en.php. Accessed on Oct. 24, 2021.

[10] Global Change Data Lab, “Onshore wind cost per kilowatt-hour, 1983 to 2017," Our World In Data, 2017. Available: https://ourworldindata.org/grapher/onshore-wind-lcoe. Accessed on Oct. 24, 2021.

[11] E. Yildiz, C. Møller, and A. Bilberg, "Virtual factory: Digital twin based integrated factory simulations," Procedia CIRP (53rd CIRP Conference on Manufacturing Systems), vol. 93, pp. 216-221, 2020. Available: https://doi.org/10.1016/j.procir.2020.04.043

[12] E. Yildiz, C. Møller, and A. Bilberg, "Demonstration and evaluation of a digital twin-based virtual factory," Int. J. Adv. Manuf. Technol., vol. 114, pp. 185-203, 2021. Available: https://doi.org/10.1007/s00170-021-06825-w

[13] E. Yildiz, C. Møller, and A. Bilberg, "Virtual Factory: Competence-Based Adaptive Modelling and Simulation Approach for Manufacturing Enterprise," 13th IFIP WG 8.1 working conference on the Practice of Enterprise Modelling, vol. 1, pp. 197-207, 2020. Available: https://doi.org/10.1007/978-3-030-63479-7_14

[14] A. Ahmad, A. M. Al-Ahmari, M. U. Aslam, M. H. Abidi, and S. Darmoul, "Virtual Assembly of an Airplane Turbine Engine," 15th IFAC Symposium on Information Control Problems in Manufacturing, 2015, vol. 28, no. 3, pp. 1726-1731, 2015. Available: https://doi.org/10.1016/j.ifacol.2015.06.335

[15] E. Yildiz, C. Møller, and A. Bilberg, "Demonstrating and Evaluating the Digital Twin Based Virtual Factory for Virtual Prototyping," Towards Sustainable Customization: Bridging Smart Products and Manufacturing Systems. CARV 2021, MCPC 2021. Lecture Notes in Mechanical Engineering, Springer, vol. pp. 297-304, 2021. Available: https://doi.org/10.1007/978-3-030-90700-6_33

[16] E. Yildiz and C. Møller, "Building a Virtual Factory: An Integrated Design Approach to Building Smart Factories," J. Glob. Oper. Strateg. Sourc., vol. 14, no. 4, pp. 608-635, 2021. Available: https://doi.org/10.1108/JGOSS-11-2019-0061

[17] E. Yildiz, C. Møller, M. Melo, and M. Bessa, "Designing Collaborative and Coordinated Virtual Reality Training Integrated with Virtual and Physical Factories," in International Conference on Graphics and Interaction 2019, pp. 48-55, 2019. Available: https://doi.org/10.1109/ICGI47575.2019.8955033

[18] J. Rix, S. Haas, and J. C. Teixeira, Virtual Prototyping - Virtual Environments and Product Design. Springer International Publishing, 1995. Available: https://doi.org/10.1007/978-0-387-34904-6

[19] G. G. Wang, "Definition and Review of Virtual Prototyping,” J. Comput. Inf. Sci. Eng., vol. 2, no. 3, p. 232, 2003. Available: https://doi.org/10.1115/1.1526508 
[20] S. H. Choi and A. M. M. Chan, "A virtual prototyping system for rapid product development," Comput. Aided Des., vol. 36, no. 5, pp. 401-412, 2004. Available: https://doi.org/10.1016/S0010-4485(03)00110-6

[21] S. Park, Y. Jun, C. Lee, and M. Yang, "Rapid Prototyping Versus Virtual Prototyping in Product Design and Manufacturing," Int. J. Adv. Manuf., vol. 70, pp. 61-70, 1993.

[22] T. Huang et al., "A virtual prototyping system for simulating construction processes," Autom. Constr., vol. 16, no. 5, pp. 576-585, 2006. Available: https://doi.org/10.1016/j.autcon.2006.09.007

[23] S. Skjong, M. Rindarøy, L. T. Kyllingstad, V. Æsøy, and E. Pedersen, "Virtual prototyping of maritime systems and operations: applications of distributed co-simulations," J. Mar. Sci. Technol., vol. 23, no. 4, pp. 835-853, 2018. Available: https://doi.org/10.1007/s00773-017-0514-2

[24] M. Karkee, B. L. Steward, A. G. Kelkar, and Z. T. Kemp, "Modeling and real-time simulation architectures for virtual prototyping of off-road vehicles," Virtual Real., vol. 15, no. 1, pp. 83-96, 2011. Available: https://doi.org/10.1007/s10055-009-0150-1

[25] S. Jayaram, H. I. Connacher, and K. W. Lyons, "Virtual assembly using virtual reality techniques," Comput. Aided Des., vol. 29, no. 8, pp. 575-584, 1997. Available: https://doi.org/10.1016/S0010-4485(96)00094-2

[26] N. Shyamsundar and R. Gadh, "Collaborative virtual prototyping of product assemblies over the Internet," CAD Comput. Aided Des., vol. 34, no. 10, pp. 755-768, $2002 . \quad$ Available: https://doi.org/10.1016/S0010-4485(01)00204-4

[27] R. Ramakrishnan and L. Gaur, "Innovation in Product Design: IoT Objects Driven New Product Innovation and Prototyping Using 3D Printers," The Internet of Things in the Modern Business Environment, pp. 189-209, IGI Global, 2017. Available: https://doi.org/10.4018/978-1-5225-2104-4.ch010

[28] K. Łukaszewicz, "Testing virtual prototype of a new product in two simulation environments," Manag. Prod. Eng. Rev., vol. 10, no. 3, pp. 124-135, 2019. Available: Available: https://doi.org/10.24425/mper.2019.130505

[29] P. J. da S. Bártolo et al., High Value Manufacturing: Advanced Research in Virtual and Rapid Prototyping: Proceedings of the 6th International Conference on Advanced Research in Virtual and Rapid Prototyping., Leiria, Portugal, 1-5 October, 2013. CRC Press.

[30] G. Todorov, K. Kamberov, T. Pantaleev, and N. Kopralev, "Elastic rail clip design development, based on virtual prototyping," IOP Conf. Ser. Mater. Sci. Eng., vol. 393, no. 1, 2018. Available: https://doi.org/10.1088/1757-899X/393/1/012120

[31] G. Ko, S. Ryu, S. Nam, J. Lee, and K. Suh, "Design of Virtual Reality Prototyping System and Hand-Held Haptic Controller," Int. J. Comput. Theory Eng., vol. 11, no. 4, pp. 72-75, 2019. Available: https://doi.org/10.7763/IJCTE.2019.V11.1245

[32] D. Mourtzis, "Simulation in the design and operation of manufacturing systems: state of the art and new trends," Int. J. Prod. Res., vol. 58, no. 7, pp. 1927-1949, 2020. Available: https://doi.org/10.1080/00207543.2019.1636321

[33] M. Onosato and K. Iwata, "Development of a Virtual Manufacturing System by Integrating Product Models and Factory Models," CIRP Ann. - Manuf. Technol., vol. 42, no. 1, pp. 475-478, 1993. Available: https://doi.org/10.1016/S0007-8506(07)62489-5

[34] M. Onosato and K. Iwata, "VirtualWorks: Building a Virtual Factory with 3-D Modelling and Object Oriented Programming Techniques," in Information Control Problems in Manufacturing Technology 1992, Elsevier, pp. 199-204, 1993. Available: https://doi.org/10.1016/B978-0-08-041897-1.50038-9

[35] S. Jain, N. F. Choong, K. M. Aye, and M. Luo, "Virtual factory: an integrated approach to manufacturing systems modeling," Int. J. Oper. Prod. Manag., vol. 21, no. 5/6, pp. 594-608, 2001. Available: https://doi.org/10.1108/01443570110390354

[36] M. Sacco, P. Pedrazzoli, and W. Terkaj, "VFF: Virtual Factory Framework," 2010 IEEE International Technology Management Conference (ICE), pp. $\quad 1-8, \quad 2010 . \quad$ Available: https://doi.org/10.1109/ICE.2010.7477041

[37] S. Jain, D. Lechevalier, J. Woo, and S. J. Shin, “Towards a virtual factory prototype," Proc. - Winter Simul. Conf., vol. 2016-Feb., pp. 2207-2218, 2016. Available: https://doi.org/10.1109/WSC.2015.7408333

[38] X. Yang et al., "Manufacturing system design with virtual factory tools," Int. J. Comput. Integr. Manuf., vol. 28, no. 1, pp. 25-40, 2015. Available: https://doi.org/10.1080/0951192X.2013.800948

[39] A. Shamsuzzoha, F. Ferreira, A. Azevedo, and P. Helo, "Collaborative smart process monitoring within virtual factory environment: an implementation issue," Int. J. Comput. Integr. Manuf., vol. 30, no. 1, pp. 167-181, 2017. Available: https://doi.org/10.1080/0951192X.2016.1185156 
[40] F. Betz, Managing technological innovation: competitive advantage from change, 3rd ed. New Jersey: John Wiley \& Sons, Inc., 1998.

[41] K. Peffers, T. Tuunanen, M. A. Rothenberger, and S. Chatterjee, “A Design Science Research Methodology for Information Systems Research,” J. Manag. Inf. Syst., vol. 24, no. 3, pp. 45-77, 2007. Available: https://doi.org/10.2753/MIS0742-1222240302

[42] A. Drechsler and A. Hevner, "A four-cycle model of IS design science research: capturing the dynamic nature of IS artifact design," in 11th International Conference on Design Science in Information Systems and Technology (DESRIST), pp. 1-8, 2016. Available: https://cora.ucc.ie/handle/10468/2560

[43] J. Van Aken, A. Chandrasekaran, and J. Halman, "Conducting and publishing design science research: Inaugural essay of the design science department of the Journal of Operations Management," J. Oper. Manag., vol. 47-48, pp. 1-8, 2016. Available: https://doi.org/10.1016/j.jom.2016.06.004

[44] R. Baskerville, A. Baiyere, S. Gregor, A. Hevner, and M. Rossi, "Design science research contributions: Finding a balance between artifact and theory," J. Assoc. Inf. Syst., vol. 19, no. 5, pp. 358-376, 2018. Available: https://doi.org/10.17705/1jais.00495

[45] J. Mokyr, “The Gifts of Athena: Historical Origins of the Knowledge Economy," Princeton University Press, 2002.

[46] E. Yildiz, “(66) Virtual Factory: A Systemic Approach to Building Smart Factories - YouTube,” Aug. 24, 2020. Available: https://www.youtube.com/watch?v=aPUfbGQc-FQ. Accessed on Feb. 06, 2021.

[47] S. Kvale, Doing Interviews. London: SAGE Publications, 2007. Available: https://doi.org/10.4135/9781849208963

[48] C. Dao, B. Kazemtabrizi, and C. Crabtree, "Wind turbine reliability data review and impacts on levelised cost of energy," Wind Energy, vol. 22, no. 12, pp. 1848-1871, 2019. Available: https://doi.org/10.1002/we.2404

[49] A. Frangoul, "Vestas invests in firm that builds wooden towers for wind turbines," CNBC, Feb. 18, 2021.

[50] S. Lonati, B. F. Quiroga, C. Zehnder, and J. Antonakis, "On doing relevant and rigorous experiments: Review and recommendations," J. Oper. Manag., vol. 64, no. October, pp. 19-40, 2018. Available: https://doi.org/10.1016/j.jom.2018.10.003 


\section{Appendix: List of Interviewees}

List of Expert Interviewees

\begin{tabular}{|c|c|c|c|c|}
\hline $\begin{array}{c}\text { Interview } \\
\text { Date \& } \\
\text { Time }\end{array}$ & No & Interviewee Title & $\begin{array}{c}\text { Years of } \\
\text { experience }\end{array}$ & Department \\
\hline \multirow{5}{*}{$\begin{array}{c}18.03 .2021 \\
\& \\
14: 30\end{array}$} & 1 & Industrialisation Lead & 12 & New Product Master (NPM) \\
\hline & 2 & Manufacturing Intelligence & 13 & $\begin{array}{l}\text { Blade Launch \& Execution Centre (BLEC), } \\
\text { Manufacturing Intelligence }\end{array}$ \\
\hline & 3 & Manager & 15 & BLEC Blade Launch Team \\
\hline & 4 & $\begin{array}{l}\text { Continuous Improvement } \\
\text { Specialist }\end{array}$ & 15 & BLEC, Continuous Improvement \\
\hline & 5 & Industrialisation Lead & 20 & Manufacturing Readiness - Blade (BLA) \\
\hline \multirow{5}{*}{$\begin{array}{c}22.03 .2021 \\
\& \\
10: 00\end{array}$} & 6 & Senior Specialist & 19 & Functional Excellence \\
\hline & 7 & $\begin{array}{l}\text { Senior Specialist, } \\
\text { Performance \& Execution }\end{array}$ & 24 & BLEC, Performance \& Execution \\
\hline & 8 & $\begin{array}{l}\text { Design for Excellence- } \\
\text { Lead Professional }\end{array}$ & 11 & Design for Manufacturing \\
\hline & 9 & $\begin{array}{l}\text { Lead Health, Safety, } \\
\text { Environment Specialist }\end{array}$ & 22 & BLEC \\
\hline & 10 & NPM Lead (Electrical) & 12 & $\begin{array}{l}\text { Manufacturing Readiness - Assembly and } \\
\text { Towers (ASSY/TOW) }\end{array}$ \\
\hline \multirow{5}{*}{$\begin{array}{c}23.03 .2021 \\
\& \\
10: 00\end{array}$} & 11 & Specialist & 11 & Manufacturing Readiness - ASSY/TOW \\
\hline & 12 & NPM Specialist & 21 & Manufacturing Readiness - BLA \\
\hline & 13 & Specialist & 13 & Manufacturing Readiness - ASSY/TOW \\
\hline & 14 & $\begin{array}{l}\text { Design for Excellence } \\
\text { Engineer }\end{array}$ & 3 & Design for Manufacturing \\
\hline & 15 & $\begin{array}{l}\text { Tooling Professional } \\
\text { Quality Tools }\end{array}$ & 15 & Manufacturing Readiness - BLA \\
\hline \multirow{5}{*}{$\begin{array}{c}29.03 .2021 \\
\& \\
14: 00\end{array}$} & 16 & NPM Lead (Blades) & 14 & Manufacturing Readiness - BLA \\
\hline & 17 & $\begin{array}{l}\text { Sr. Manager, Training \& } \\
\text { Global Transfer }\end{array}$ & 10 & Global Training \& Knowledge Transfer \\
\hline & 18 & $\begin{array}{l}\text { NC Tech Continuous } \\
\text { Improvement lead }\end{array}$ & 13 & Manufacturing Readiness - NC TECH \\
\hline & 19 & NPM Lead (Towers) & 13 & Manufacturing Readiness - ASSY/TOW \\
\hline & 20 & Specialist & 21 & Manufacturing Readiness - ASSY/TOW \\
\hline
\end{tabular}

